\title{
Concentration, sources and light absorption characteristics of dissolved organic carbon on a medium-sized valley glacier, northern Tibetan Plateau
}

\author{
Fangping Yan ${ }^{1,4,5}$, Shichang Kang ${ }^{1,3,4}$, Chaoliu $\mathbf{L i}^{2,3}$, Yulan Zhang ${ }^{1}$, Xiang Qin ${ }^{1}$, Yang $\mathbf{~ L i}^{2,4}$, Xiaopeng Zhang ${ }^{1,4}$, \\ Zhaofu $\mathrm{Hu}^{1,4}$, Pengfei Chen ${ }^{2}$, Xiaofei $\mathbf{L i}^{1}$, Bin $\mathbf{Q u}^{5}$, and Mika Sillanpää ${ }^{5,6}$ \\ ${ }^{1}$ Qilian Station for Glaciology and Ecological Environment, State Key Laboratory of Cryospheric Sciences, Northwest \\ Institute of Eco-Environment and Resources, Chinese Academy of Sciences, 730000 Lanzhou, China \\ ${ }^{2}$ Key Laboratory of Tibetan Environment Changes and Land Surface Processes, Institute of Tibetan Plateau Research, \\ Chinese Academy of Sciences, 100101 Beijing, China \\ ${ }^{3}$ CAS Center for Excellence in Tibetan Plateau Earth Sciences, Chinese Academy of Sciences, 100101 Beijing, China \\ ${ }^{4}$ University of Chinese Academy of Sciences, 100049 Beijing, China \\ ${ }^{5}$ Laboratory of Green Chemistry, Lappeenranta University of Technology, Sammonkatu 12, 50130 Mikkeli, Finland \\ ${ }^{6}$ Department of Civil and Environmental Engineering, Florida International University, Miami, FL 33174, USA
}

Correspondence to: Shichang Kang (shichang.kang@1zb.ac.cn) and Chaoliu Li (lichaoliu@itpcas.ac.cn)

Received: 24 February 2016 - Published in The Cryosphere Discuss.: 11 April 2016

Revised: 3 October 2016 - Accepted: 17 October 2016 - Published: 7 November 2016

\begin{abstract}
Light-absorbing dissolved organic carbon (DOC) constitutes a major part of the organic carbon in glacierized regions, and has important influences on the carbon cycle and radiative forcing of glaciers. However, few DOC data are currently available from the glacierized regions of the Tibetan Plateau (TP). In this study, DOC characteristics of a mediumsized valley glacier (Laohugou Glacier No. 12, LHG) on the northern TP were investigated. Generally, DOC concentrations on LHG were comparable to those in other regions around the world. DOC concentrations in snow pits, surface snow and surface ice (superimposed ice) were $332 \pm 132$, $229 \pm 104$ and $426 \pm 270 \mu \mathrm{g} \mathrm{L}{ }^{-1}$, respectively. The average discharge-weighted DOC of proglacial stream water was $238 \pm 96 \mu \mathrm{g} \mathrm{L}^{-1}$, and the annual DOC flux released from this glacier was estimated to be $6949 \mathrm{~kg} \mathrm{Cyr}^{-1}$, of which $46.2 \%$ of DOC was bioavailable and could be decomposed into $\mathrm{CO}_{2}$ within 1 month of its release. The mass absorption cross section (MAC) of DOC at $365 \mathrm{~nm}$ was $1.4 \pm 0.4 \mathrm{~m}^{2} \mathrm{~g}^{-1}$ in snow and $1.3 \pm 0.7 \mathrm{~m}^{2} \mathrm{~g}^{-1}$ in ice, similar to the values for dust transported from adjacent deserts. Moreover, there was a significant relationship between DOC and $\mathrm{Ca}^{2+}$; therefore, mineral dust transported from adjacent arid regions likely made important contributions to DOC of the glacierized regions, although contributions from autochthonous carbon and au-
\end{abstract}

tochthonous/heterotrophic microbial activity cannot be ruled out. The radiative forcing of snow pit DOC was calculated to be $0.43 \mathrm{~W} \mathrm{~m}^{-2}$, demonstrating that DOC in snow needs to be taken into consideration in accelerating melt of glaciers on the TP.

\section{Introduction}

Ice sheets and mountain glaciers cover $11 \%$ of the land surface of the Earth and store approximately $6 \mathrm{Pg}$ $\left(1 \mathrm{Pg}=10^{15} \mathrm{~g}\right)$ of organic carbon, the majority of which $(77 \%)$ is in the form of dissolved organic carbon (DOC) (Hood et al., 2015). The annual global DOC release through glacial run-off is around $1.04 \pm 0.18 \mathrm{TgC}\left(1 \mathrm{Tg}=10^{12} \mathrm{~g}\right)$ (Hood et al., 2015). Therefore, glaciers not only play an important role in the hydrological cycle by contributing to sea level (Jacob et al., 2012) and endorheic basins (Neckel et al., 2014), but also potentially influence the global carbon cycle (Anesio and Laybourn-Parry, 2012; Hood et al., 2015) in the context of accelerated glacial ice loss rates. In addition, a large portion of glacier-derived DOC has proven to be highly bioavailable, influencing the balance of downstream ecosys- 
tems (Hood et al., 2009; Singer et al., 2012; Spencer et al., 2014).

Although DOC storage in ice sheets is much larger than that of mountain glaciers, the annual mountain glacierderived DOC dominates the global DOC release (Hood et al., 2015). Currently, there are studies on DOC concentrations, ages and compositions of glaciers in Alaska (Stubbins et al., 2012; Hood et al., 2009), DOC bioavailability of glaciers on the Tibetan Plateau (TP) and the Greenland Ice Sheet (Spencer et al., 2014; Lawson et al., 2014) and DOC storage and export of the whole glacier regions around the world (Hood et al., 2015). The sources of glacier DOC are diverse and include autochthonous or in situ biological activities (Anesio et al., 2009), allochthonous carbon derived from overridden soils and vegetation (Bhatia et al., 2010), terrestrial inputs (DOC deposition from vascular plants and dust) (Singer et al., 2012) and anthropogenic sources (Stubbins et al., 2012). Moreover, research on glacier microbial activity suggests that globally cryoconite holes alone can potentially fix about $64 \mathrm{Gg} \mathrm{C} \mathrm{yr}^{-1}$ (Anesio et al., 2009). Meanwhile, there are large variations in glacier DOC concentrations and ages (Singer et al., 2012; Hood et al., 2015; Antony et al., 2011). For example, the concentration of total organic carbon in snow across the East Antarctic Ice Sheets exhibited remarkable spatial variations due to the marine source of organic carbon (Antony et al., 2011). Studies of both radiocarbon isotopic compositions and biodegradable DOC (BDOC) have proposed that ancient organic carbon from glaciers is much easier for microbes to utilize in glacier-fed rivers and oceans, implying that large amounts of this DOC will return to the atmosphere quickly as $\mathrm{CO}_{2}$ and participate in the global carbon cycle, thereby producing a positive feedback in the global warming process (Hood et al., 2009; Singer et al., 2012; Spencer et al., 2014).

In addition to black carbon (BC), another DOC fraction known as water-soluble brown carbon has also been considered as a warming component in the climate system (Andreae and Gelencsér, 2006; Chen and Bond, 2010). This type of DOC exhibits strong light-absorbing properties in the ultraviolet wavelengths (Andreae and Gelencsér, 2006; Chen and Bond, 2010; Cheng et al., 2011). The radiative forcing caused by water-soluble organic carbon (the same as DOC) relative to $\mathrm{BC}$ in aerosols was estimated to account for $2-10 \%$ in a typical pollution area of North China (Kirillova et al., 2014a) and approximately $1 \%$ at a remote island in the Indian Ocean (Bosch et al., 2014), respectively. Unfortunately, to date, few direct evaluations have been conducted in the glacierized regions around the world, including the TP, where DOC accounts for a large part of the carbonaceous matter (Legrand et al., 2013; May et al., 2013) and potentially contributes significantly to the radiative forcing.

The TP has the largest number of glaciers at moderate elevations. Most of the glaciers on the TP are experiencing intensive retreat because of multiple reasons such as climatic conditions (Kehrwald et al., 2008; Bolch et al., 2012;
Yao et al., 2012; Kang et al., 2015) and anthropogenic carbonaceous particle deposition (Xu et al., 2009; Lau et al., 2010; Nair et al., 2013; Kaspari et al., 2014). However, to date, no study has quantitatively evaluated the light absorption characteristics of DOC in the glacierized regions on the TP, despite some investigations of concentrations, bioavailability age and sources of DOC (Spencer et al., 2014; Yan et al., 2015). The primary results of these studies have shown that DOC concentrations in snow pits at sites on the northern TP are higher than those on the southern TP (Yan et al., 2015). In addition, a large fraction of the ancient DOC in the glaciers on the southern TP is highly bioavailable (Spencer et al., 2014). Knowledge of DOC in TP glaciers remains lacking due to the large area and diverse environments of the TP in contrast to the relatively limited samples and studies. Therefore, this study is to comprehensively investigate the sources, light absorption properties and carbon dynamics on Laohugou Glacier No. 12 (LHG). The results will provide a basis for the study of DOC across the TP and other regions in the future.

\section{Methodology}

\subsection{Study area and sampling site}

LHG $\left(39^{\circ} 05^{\prime}-40^{\prime} \mathrm{N}, 96^{\circ} 07^{\prime}-97^{\circ} 04^{\prime} \mathrm{E} ; 4260-5481 \mathrm{~m}\right)$ is the largest mountain glacier $\left(9.85 \mathrm{~km}, 20.4 \mathrm{~km}^{2}\right)$ in the Qilian Mountains, and is located on the northeastern edge of the TP (Du et al., 2008; Dong et al., 2014a). It divides western and eastern branches at an elevation of $4560 \mathrm{~m}$ a.s.l. (Dong et al., 2014a). The glacier is surrounded by extensive large arid and semi-arid regions (sandy deserts and the Gobi Desert) and is frequently influenced by strong dust storms (Dong et al., 2014b) (Fig. 1), and it covers an area of approximately $53.6 \%$ of the entire LHG basin (Du et al., 2008; Li et al., 2012).

LHG has typical continental and arid climate characteristics (Li et al., 2012; Zhang et al., 2012b). Precipitation from May to September accounts for over $70 \%$ of the annual total amount (Zhang et al., 2012b). The monthly mean air temperature in the ablation zone of the glacier ranges from $-18.4^{\circ} \mathrm{C}$ in December to $3.4^{\circ} \mathrm{C}$ in July (Li et al., 2012). Like other glaciers on the TP, LHG has been experiencing significant thinning and shrinkage at an accelerated rate since the mid1990s (Du et al., 2008; Zhang et al., 2012b).

\subsection{Sample collection}

Two snow pits were dug in 2014 and 2015 at almost the same location in the accumulation zone of LHG. In total, 15 and 23 snow samples were collected from these pits in 2014 and 2015 , respectively, at a vertical resolution of $5 \mathrm{~cm}$. Moreover, 29 surface snow and 42 surface ice samples were collected along the eastern tributary from the terminus to the accumulation zone at an approximate elevation interval of 50 or 
Table 1. Sampling information for snow, ice and proglacial stream water in this study.

\begin{tabular}{|c|c|c|c|c|c|}
\hline Sample type & Sampling time & Resolution* & Sampling site & Number $(n)$ & Index \\
\hline Snow pit & 30 July 2014 & $5 \mathrm{~cm}$ & $4989 \mathrm{~m}$ & 15 & DOC, absorbance, ions \\
\hline Snow pit & 25 August 2015 & $5 \mathrm{~cm}$ & $5050 \mathrm{~m}$ & 23 & DOC, absorbance, ions \\
\hline Surface fresh snow & 4 August 2014 & $100 \mathrm{~m}$ & $4450-4900 \mathrm{~m}$ & 18 & DOC \\
\hline Surface ice & 6 August 2014 & $100 \mathrm{~m}$ & $4350-4900 \mathrm{~m}$ & 20 & DOC \\
\hline Surface snow & 16 July 2015 & $50 \mathrm{~m}$ & $4350-4850 \mathrm{~m}$ & 11 & DOC \\
\hline Surface ice & 15 August 2015 & $50 \mathrm{~m}$ & $4350-4850 \mathrm{~m}$ & 11 & DOC \\
\hline Surface ice & 25 August 2015 & $50 \mathrm{~m}$ & $4350-4600 \mathrm{~m}$ & 6 & DOC, absorbance \\
\hline Subsurface ice & 25 August 2015 & $50 \mathrm{~m}$ & $4350-4600 \mathrm{~m}$ & 5 & DOC, absorbance \\
\hline Proglacial stream water & 29-30 July 2014 & $2 \mathrm{~h}$ (day), $4 \mathrm{~h}$ (night) & $4210 \mathrm{~m}$ & 17 & DOC \\
\hline Proglacial stream water & 20 May-9 October 2015 & Every day & $4210 \mathrm{~m}$ & 184 & DOC \\
\hline
\end{tabular}

* Vertical resolution (snow pit) or horizontal distance (surface snow and ice).

$100 \mathrm{~m}$, and 201 proglacial stream water samples were collected at the gauge station during the melting period (Fig. 1, Table 1). The concentrations of glacier DOC have been observed to be very low and are prone to contamination, often causing an overestimation of DOC concentrations (Legrand et al., 2013). Therefore, before sample collection, polycarbonate bottles were firstly washed three times using ultrapure water, then soaked with $1 \mathrm{M} \mathrm{HCl}$ for $24 \mathrm{~h}$ (Spencer et al., 2009), rinsed three times using ultrapure water and finally soaked in ultrapure water for over $24 \mathrm{~h}$. Throughout the sampling period, snow samples were collected directly into $125 \mathrm{~mL}$ pre-cleaned bottles, surface ice $(0-3$ and $3-$ $5 \mathrm{~cm}$ ) samples were collected using an ice axe directly into polycarbonate bottles after crushing, while proglacial stream water samples were filtered immediately after collection before being transferred into bottles. All ice and snow samples were filtered as soon as possible after they were melted. To prevent contamination, sampling personnel were careful to avoid touching any other surfaces whilst carrying out the sample collection. At least one blank was made for every sampling process to confirm that the contamination was low (Table S1 in the Supplement). Meanwhile, another batch of samples was also collected for $\mathrm{BC}$ analysis following the protocol discussed in detail in our earlier study (Qu et al., 2014); these results are subjected to future work. In order to evaluate DOC discharge from the entire TP, DOC concentrations in proglacial stream water samples from a further five glaciers were also measured during monsoon and non-monsoon seasons (Fig. 1, Table S2 in the Supplement).

All the collected samples were kept frozen and in the dark during storage in the field, transportation and in the laboratory until analysis. In addition, four dust fall samples from Dunhuang, a desert location $\left(39^{\circ} 53^{\prime}-41^{\circ} 35^{\prime} \mathrm{N}, 92^{\circ} 13^{\prime}-\right.$ $93^{\circ} 30^{\prime} \mathrm{E}$ ) and potential source region for dust deposited on LHG, were collected to compare the light absorption characteristics of dust-sourced DOC to those of the snow pit and ice samples. Mineral and elemental compositions of desert sands of west China have been homogenized by aeolian ac- tivity (Hattori et al., 2003), so that the dust samples collected in this study are representative of desert-sourced dust in west China.

\subsection{Laboratory analyses}

\subsubsection{Concentration measurements of DOC and major ions}

DOC concentrations were determined using a TOC-5000A analyzer (Shimadzu Corp, Kyoto, Japan) following filtration through a PTFE membrane filter with $0.45 \mu \mathrm{m}$ pore size (Macherey-Nagel) (Yan et al., 2015). The detection limit of the analyzer was $15 \mu \mathrm{gL}^{-1}$, and the average DOC concentration of the blanks was $32 \pm 7 \mu \mathrm{g} \mathrm{L}^{-1}$, demonstrating that contamination can be ignored during the pre-treatment and analysis processing of these samples (Table $\mathrm{S} 1$ in the Supplement). The major cations $\left(\mathrm{Ca}^{2+}, \mathrm{Mg}^{2+}, \mathrm{Na}^{+}, \mathrm{K}^{+}\right.$ and $\left.\mathrm{NH}_{4}^{+}\right)$and major anions $\left(\mathrm{Cl}^{-}, \mathrm{NO}_{3}^{-}\right.$and $\left.\mathrm{SO}_{4}^{2-}\right)$ were measured using a Dionex-6000 Ion Chromatograph and a Dionex-3000 Ion Chromatograph (Dionex, USA), respectively. The detection limit was $1 \mu \mathrm{g} \mathrm{L}^{-1}$, and the standard deviation was less than $5 \%$ (Li et al., 2007, 2010). The average ion concentrations of the blanks were very low and could be ignored $\left(\mathrm{Na}^{+}, \mathrm{K}^{+}, \mathrm{Mg}^{2+}, \mathrm{F}^{+}, \mathrm{SO}_{4}^{2-}, \mathrm{Cl}^{-}, \mathrm{NO}_{3}^{-}<1 \mu \mathrm{g} \mathrm{L}^{-1}\right.$; $\left.\mathrm{NH}_{4}^{+}=1.4 \mu \mathrm{g} \mathrm{L}^{-1} ; \mathrm{Ca}^{2+}=1.2 \mu \mathrm{g} \mathrm{L}^{-1}\right)$.

\subsubsection{Light absorption measurements}

The light absorption spectra of DOC samples were measured using an ultraviolet-visible absorption spectrophotometer (SpectraMax M5, USA), scanning wavelengths from 200 to $800 \mathrm{~nm}$ at a precision of $5 \mathrm{~nm}$. The mass absorption cross section (MAC) was calculated based on the Lambert-Beer law (Bosch et al., 2014; Kirillova et al., 2014a, b):

$\mathrm{MAC}_{\mathrm{DOC}}=\frac{-\ln \left|\frac{I}{I_{0}}\right|}{C \cdot L}=\frac{A}{C \cdot L} \times \ln (10)$, 


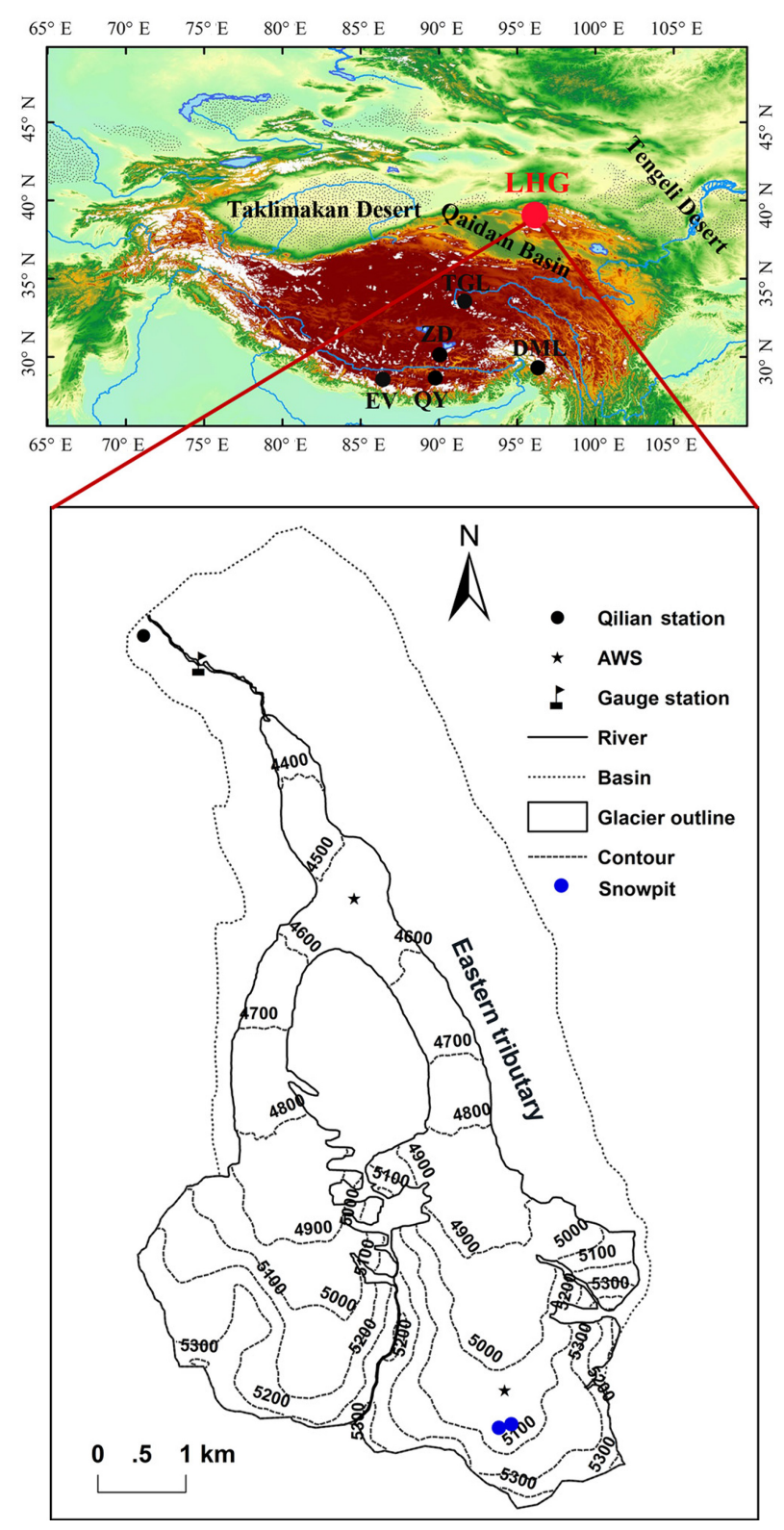

Figure 1. Location map of LHG No. 12.

where $I_{0}$ and $I$ are the light intensities of the transmitted light and incident light, respectively; $A$ is the absorbance derived directly from the spectrophotometer; $C$ is the concentration of DOC; and $L$ is the absorbing path length $(1 \mathrm{~cm})$.

In order to investigate the wavelength dependence of DOC light absorption characteristics, the absorption Ångström exponent (AAE) was fitted by the following equation (Kirillova et al., 2014a, b):

$\frac{A\left(\lambda_{1}\right)}{A\left(\lambda_{2}\right)}=\left(\frac{\lambda_{2}}{\lambda_{1}}\right)^{\mathrm{AAE}}$.

AAE values were fitted for wavelengths of 330 to $400 \mathrm{~nm}$; within this wavelength range, light absorption by other in- organic compounds (such as nitrate) can be avoided (Cheng et al., 2011). The radiative forcing caused by $\mathrm{BC}$ has been widely studied (Ming et al., 2013; Kaspari et al., 2014; Qu et al., 2014). Therefore, using a simplistic model (the following algorithm) in this study, the amount of solar radiation absorbed by DOC compared to BC was estimated:

$$
f=\frac{\int_{300}^{2500} I_{0}(\lambda) \cdot\left\{1-e^{-\left(\operatorname{MAC}_{365}\left(\frac{365}{\lambda}\right)^{\mathrm{AAE}_{\mathrm{DOC}}} \cdot C_{\mathrm{DOC}} \cdot h_{\mathrm{ABL}}\right)}\right\} \mathrm{d} \lambda}{\int_{300}^{2500} I_{0}(\lambda) \cdot\left\{1-e^{-\left(\mathrm{MAC}_{550}\left(\frac{550}{\lambda}\right)^{\mathrm{AAE} \mathrm{BC}} \cdot C_{\mathrm{EC}} \cdot h_{\mathrm{ABL}}\right)}\right\} \mathrm{d} \lambda},
$$

where $\lambda$ is the wavelength; $I_{0}(\lambda)$ is the clear sky solar emission spectrum determined using the Air Mass 1 Global Horizontal (AM1GH) irradiance model (Levinson et al., 2010); $\mathrm{MAC}_{365}$ and $\mathrm{MAC}_{550}$ are the mass absorption cross section of DOC at $365 \mathrm{~nm}$ and mass absorption cross section of BC at $550 \mathrm{~nm}$, respectively; $h_{\mathrm{ABL}}$ is the vertical height of the atmospheric boundary layer; and $\mathrm{AAE}_{\mathrm{DOC}}$ and $\mathrm{AAE}_{\mathrm{BC}}$ are the absorption Ångström exponents (AAEs) of DOC and BC. In this simplistic model, we used $\mathrm{MAC}_{550}=7.5 \pm 1.2 \mathrm{~m}^{2} \mathrm{~g}^{-1}$ (following Bond and Bergstrom, 2006), AAE for BC was set as 1 , and $h_{\mathrm{ABL}}$ was set to $1000 \mathrm{~m}$, which has little influence on the integration from the wavelengths of $300-2500 \mathrm{~nm}$ (Bosch et al., 2014; Kirillova et al., 2014a, b). It is obvious that the value of $f$ is closely connected to the relative concentrations of DOC and BC.

\subsubsection{In situ DOC bioavailability experiment}

The bioavailability experiment was conducted during fieldwork from 17 to 31 August 2015 at the glacier terminus. In brief, surface ice samples were collected in pre-combusted $\left(550^{\circ} \mathrm{C}, 6 \mathrm{~h}\right)$ aluminium basins and melted in the field. The melted samples were filtered through pre-combusted glass fibre filters $(\mathrm{GF} / \mathrm{F} 0.7 \mu \mathrm{m})$ into 12 pre-cleaned $125 \mathrm{~mL}$ polycarbonate bottles and wrapped with three layers of aluminum foil to avoid solar irradiation. Two samples were refrigerated immediately after filtering to obtain initial DOC concentrations; the others were placed outside at the terminus of the glacier, and two samples were refrigerated every 3 days to obtain corresponding DOC values. The BDOC was calculated based on the discrepancies between the initial and treated samples.

\section{Results and discussion}

\subsection{DOC concentrations and bioavailability}

\subsubsection{Snow pits}

The average DOC concentration in the snow pit samples was $332 \pm 132 \mu \mathrm{g} \mathrm{L}{ }^{-1}$ (Fig. 2), with values ranging from 124 to $581 \mu \mathrm{g} \mathrm{L}^{-1}$ (Fig. 3). The highest values occurred in the 
Table 2. Comparison of DOC concentrations in snow, ice and proglacial stream water from the glacier in this study and glaciers in other regions.

\begin{tabular}{llll}
\hline Sites & DOC concentration $\left(\mu \mathrm{L}^{-1}\right)$ & Sample types & References \\
\hline Laohugou Glacier (LHG) & $332 \pm 132$ & Snow pit & This study \\
Tanggula Glacier (TGL) & $217 \pm 143$ & Snow pit & Yan et al. (2015) \\
Mount Everest (EV) & $153 \pm 561$ & Snow pit & Yan et al. (2015) \\
Mendenhall Glacier, Alaska & 190 & Snow pit & Stubbins et al. (2012) \\
Greenland Ice Sheet & $40-57$ & Snow pit & Hagler et al. (2007) \\
Laohugou Glacier (LHG) & $229 \pm 104$ & Surface snow & This study \\
Greenland Ice Sheet & 111 & Surface snow & Hagler et al. (2007) \\
Juneau Icefield, Southeast Alaska & $100-300$ & Fresh snow/snow pits & Fellman et al. (2015) \\
Laohugou Glacier (LHG) & $426 \pm 270$ & Surface ice & This study \\
Mount Nyainqêntanglha Glacier & 212 & Glacier ice & Spencer et al. (2014) \\
Antarctic Ice Sheet & $460 \pm 120$ & Surface ice & Hood et al. (2015) \\
Alpine glacier & $138 \pm 96$ & Subsurface ice & Singer et al. (2012) \\
Laohugou Glacier (LHG) & $238 \pm 96$ & Proglacial stream water & This study \\
Mount Nyainqêntanglha Glacier & 262 & Proglacial stream water & Spencer et al. (2014) \\
Mendenhall Glacier, Alaska & $380 \pm 20$ & Proglacial stream water & Stubbins et al. (2012) \\
\hline
\end{tabular}

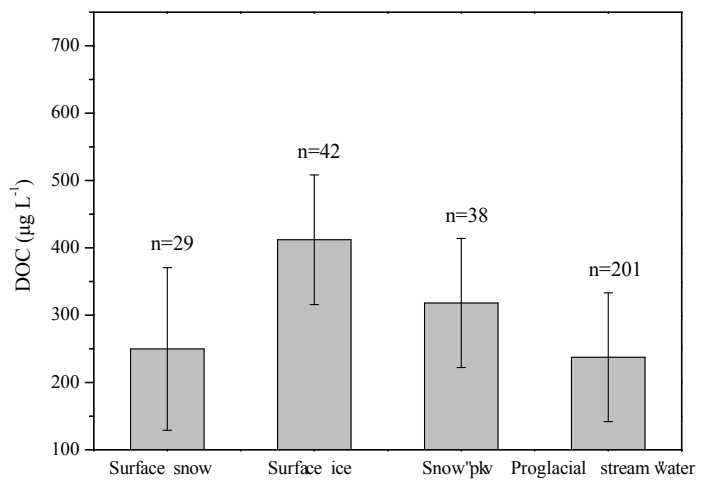

Figure 2. Average DOC concentrations of ice, snow and proglacial stream water for LHG.

dirty layers (Fig. 3), similar to the pattern observed at the Greenland summit (Hagler et al., 2007) and in glaciers on the southern TP (Xu et al., 2013), indicating that DOC concentrations in the study area were probably influenced by desert-sourced mineral dust deposition from adjacent arid regions and the frequent dust storms. Spatially, our results were higher than those of Xiaodongkemadi Glacier on Mountain Tanggula (TGL) in the central TP and the east Rongbu Glacier on Mount Everest (EV) on the southern TP (Fig. 1) (Yan et al., 2015); however, they follow a similar pattern to that of the mercury distribution on the TP (Zhang et al., 2012a). In addition, the DOC concentrations on LHG were also higher than those of Mendenhall Glacier, Alaska (Stubbins et al., 2012) and the Greenland summit (Table 2) (Hagler et al., 2007).

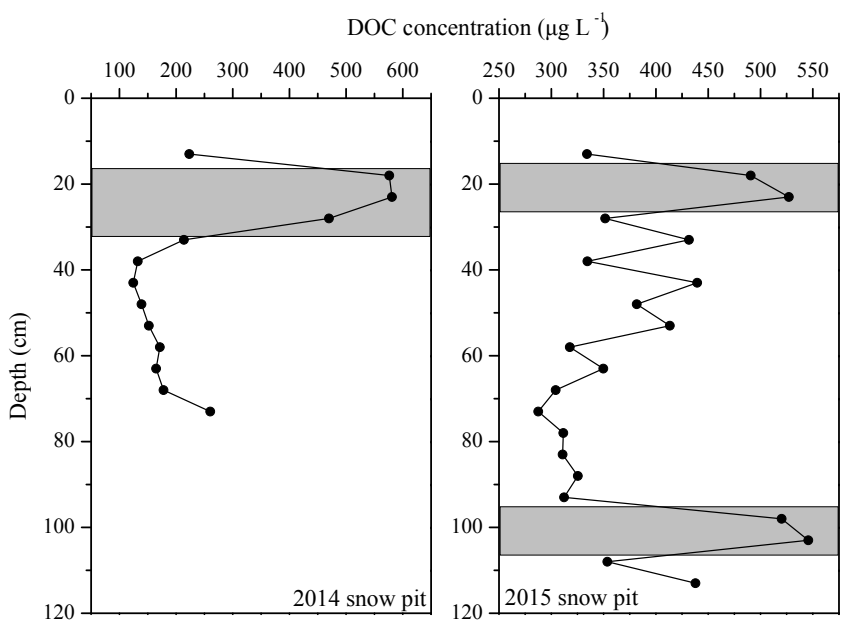

Figure 3. Variation in DOC concentrations in profiles of studied snow pits. The gray rectangles are dirty layers.

\subsubsection{Surface snow and ice}

The average DOC concentration in LHG surface snow was significantly lower than that in surface ice because more impurities are present in the latter (Fig. 2). Like those of the snow pits, DOC concentrations in the glacier surface ice (Fig. 2) were higher than those on the southern TP (Nyainqêntanglha Glacier) (Spencer et al., 2014) and subsurface ice $(0.5 \mathrm{~m}$ beneath the glacier surface) in a European Alpine glacier (Singer et al., 2012) (Table 2), but comparable to that in the surface ice of the Antarctic Ice Sheet (Hood et al., 2015). However, the DOC concentrations in surface snow (Table 2) were higher than those in the Greenland Ice Sheet (Hagler et al., 2007), mainly due to the heavy dust load on LHG. No significant relationship was found between DOC 


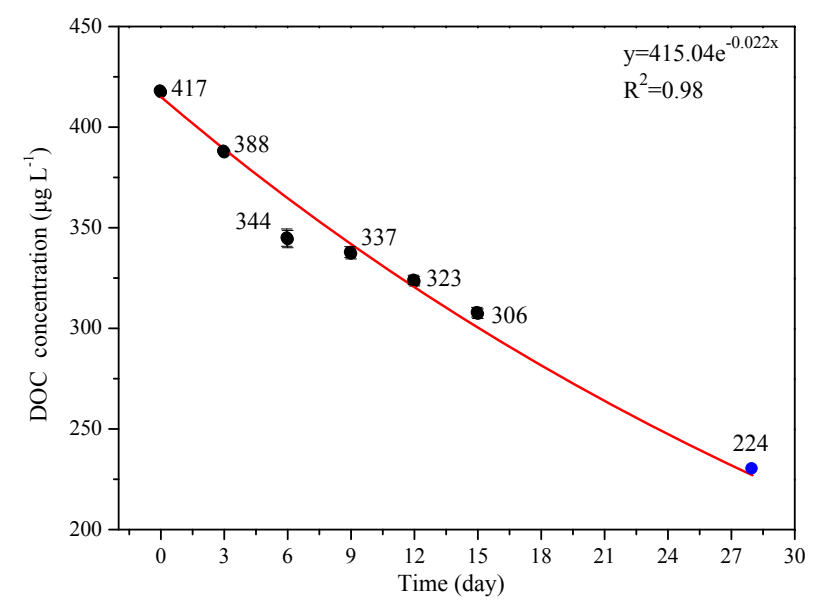

Figure 4. Exponential deceases in DOC concentrations during the biodegradation experiment. The blue point is calculated using equations derived from the experimental data (black points).

concentration and elevation for either the surface snow or ice (Fig. S1 in the Supplement), suggesting there is no link between altitude and DOC at this glacier. Similar weak correlation with altitude at LHG was also found with mercury (Huang et al., 2014). Therefore, the distributions of DOC concentrations in the glacier surface snow and ice were influenced by other complex factors, such as different slopes (Hood and Scott, 2008) and cryoconite holes. Furthermore, DOC concentrations in snow and ice at this glacier were within the range of previously reported values for glacierized regions outside the TP.

\subsubsection{DOC bioavailability}

The in situ bioavailability experiment results showed that the amount of DOC being consumed decreased exponentially over time $\left(R^{2}=0.98\right)$ (Fig. 4$)$, with approximately $26.7 \%$ (from 417 to $306 \mu \mathrm{g} \mathrm{L}^{-1}$ ) degraded within 15 days during the experiment (average temperature: $3.8 \pm 3.7^{\circ} \mathrm{C}$; range: -4.8 to $11.4{ }^{\circ} \mathrm{C}$ ). The BDOC would have reached $46.3 \%$ if the experiment duration had been extended to 28 days, according to the equation derived from the 15 days' experiment (Fig. 4). Despite different incubation conditions, this result agrees well with the reports of BDOC from a glacier on the southern TP (28 days dark incubation at $20^{\circ} \mathrm{C}, 46-69 \%$ BDOC) (Spencer et al., 2014) and from European Alpine glaciers (50 days dark incubation at $4{ }^{\circ} \mathrm{C}, 59 \pm 20 \%$ BDOC) (Singer et al., 2012). Therefore, the previous results obtained in the laboratory closely reflect the in situ situation and can be used to estimate the bioavailability of glacier-derived DOC.

\subsection{Sources of snow pit DOC}

In this study, major ions were adopted as indicators to investigate the potential sources of snow pit DOC because the sources of major ions in snow pit samples from Tibetan glaciers have previously been investigated in detail (Kang et al., 2002, 2008; Wu et al., 2011; Yan et al., 2015). Moreover, the DOC profiles in two snow pits varied with the dust content; specifically, DOC concentration of dust layers was much higher than that of clean layers. Furthermore, it was found that DOC and $\mathrm{Ca}^{2+}$ (a typical indicator of mineral dust; Yao, 2004) were significantly correlated $\left(R^{2}=0.84\right.$, Fig. S2 in the Supplement), suggesting that the major source of DOC was desert-sourced mineral dust, similar to the previous investigations of DOC sources of snow pits at this glacier (Yan et al., 2015). Combining geochemical and backward trajectories' analysis at LHG, this further supports the interpretation that dust particles on the glacier were mainly derived from the deserts to the west and north of the study area (Dong et al., 2014a, b). Despite this potential source, local anthropogenic pollutants (biomass, fossil fuel combustion and other activities) (Yan et al., 2015) and biological activities on glacier surface (Anesio et al., 2009) may also contribute to the glacier DOC.

\subsection{Light absorption characteristics of DOC}

\subsubsection{AAE}

The absorption Ångström exponent (AAE) is generally used to characterize the spectral dependence of the light absorption of DOC, thereby providing important input data for radiative forcing calculations. The fitted $\mathrm{AAE}_{330-400}$ values ranged from 1.2 to $15.2(5.0 \pm 5.9)$ for snow samples and from 0.3 to $8.4(3.4 \pm 2.7)$ for ice samples (Fig. S4 in the Supplement). The relatively low $\mathrm{AAE}_{330-400}$ values for ice indicated that the DOC had experienced strong photobleaching caused by long-term exposure to solar irradiation. Previous studies have found that the AAE values of brown carbon in aged aerosols (Zhao et al., 2015) and secondary organic aerosols (SOAs) (Lambe et al., 2013) were much lower than their respective primary values. Therefore, the wide divergence in AAE values might suggest different chemical compositions of DOC due to multiple factors, such as different sources and photobleaching processes. Regardless, the average AAE value of the snow samples was comparable to that of atmospheric aerosols in urban areas in South Asia (New Delhi, India) (Kirillova et al., 2014b) (Table 2). In general, the $\mathrm{AAE}_{330-400}$ values had a negative relationship with $M A C_{365}$, especially in the ice samples (Fig. S4 in the Supplement), suggesting that the more strongly absorbing DOC might contribute to lower AAE values, as has been observed in previous aerosol studies (Chen and Bond, 2010; Bosch et al., 2014; Kirillova et al., 2014b).

\subsection{2 $\mathrm{MAC}_{365}$}

The mass absorption cross section at $365 \mathrm{~nm}\left(\mathrm{MAC}_{365}\right)$ for DOC is another input parameter for the radiative forcing calculation. The light absorption ability at $365 \mathrm{~nm}$ was selected 
Table 3. Mass absorption cross section (MAC) and absorption Ångström exponent ( $\mathrm{AAE}_{330-400)}$ of ice and snow from LHG and aerosols from other regions.

\begin{tabular}{|c|c|c|c|c|}
\hline Site/source & $\operatorname{MAC}\left(\mathrm{m}^{2} \mathrm{~g}^{-1}\right)$ & $\mathrm{AAE}_{330-400}$ & $\lambda(\mathrm{MAC})$ & References \\
\hline \multirow[t]{2}{*}{ LHG } & $1.4 \pm 0.4($ snow $)$ & $5.0 \pm 5.9($ snow $)$ & 365 & This study \\
\hline & $1.3 \pm 0.7$ (ice) & $3.4 \pm 2.7$ (ice) & & \\
\hline Biomass smoke & 5.0 & 4.8 & 350 & Kirchstetteret al. (2004) \\
\hline Secondary organic aerosols & $0.001-0.088$ & $5.2-8.8$ & 405 & Lambe et al. (2013) \\
\hline Wood smoke & $0.13-1.1$ & $8.6-17.8$ & 400 & Chen and Bond (2010) \\
\hline HULIS, Arctic snow & $2.6 \pm 1.1$ & $6.1^{*}$ & 250 & Voisin et al. (2012) \\
\hline Beijing, China (winter) & $1.79 \pm 0.24$ & 7.5 & 365 & Cheng et al. (2011) \\
\hline Beijing, China (summer) & $0.71 \pm 0.20$ & 7.1 & 365 & Cheng et al. (2011) \\
\hline
\end{tabular}

* The wavelength range for AAE in this study is $300-550 \mathrm{~nm}$.

to avoid interferences of non-organic compounds (such as nitrate) and for consistency with previous investigations (Hecobian et al., 2010; Cheng et al., 2011). The $\mathrm{MAC}_{365}$ was $1.4 \pm 0.4 \mathrm{~m}^{2} \mathrm{~g}^{-1}$ in snow and $1.3 \pm 0.7 \mathrm{~m}^{2} \mathrm{~g}^{-1}$ in glacier ice (Fig. S4 in the Supplement), both of which were higher than those of water-soluble organic carbon in an outflow in northern China (Kirillova et al., 2014a) and on a receptor island in the Indian Ocean (Bosch et al., 2014). Meanwhile, the values were comparable to DOC concentrations in typical urban aerosols associated with biomass combustion in winter in Beijing, China (Cheng et al., 2011) and in New Delhi, India (Kirillova et al., 2014b) (Table 3). The MAC values for DOC from different sources vary widely. Typically, the $\mathrm{MAC}_{365}$ of DOC derived from biomass combustion can reach $5 \mathrm{~m}^{2} \mathrm{~g}^{-1}$ (Kirchstetter, 2004) (Table 3). Correspondingly, the values for SOAs can be as low as $0.001-0.088 \mathrm{~m}^{2} \mathrm{~g}^{-1}$ (Lambe et al., 2013). Due to the remote location of LHG, it was considered that the snow pit DOC should comprise SOAs with low $\mathrm{MAC}_{365}$ values; however, the high $\mathrm{MAC}_{365}$ value of the snow pit DOC indicated that DOC may not be entirely derived from SOAs. Hence, it was proposed that mineral-dustsourced DOC caused the high $\mathrm{MAC}_{365}$ values in the snow pit samples. For instance, the light absorption characteristics of DOC from both snow pit and ice samples showed similar patterns to those of water-soluble organic carbon in dust from the adjacent deserts, further indicating that LHG DOC was transported via desert-sourced mineral dust, and shared similar light absorption characteristics (Fig. 5). Moreover, the difference in light absorption characteristics (especially for wavelengths larger than $400 \mathrm{~nm}$ ) between snow/ice samples and aerosols in Beijing, China, also indicated their different sources (Fig. 5). Light absorbance was significantly correlated with DOC concentrations in both snow and ice samples (Fig. S3 in the Supplement), indicating that DOC was one of the absorption factors. Nevertheless, the $\mathrm{MAC}_{365}$ values of surface ice $(0-3 \mathrm{~cm})$ were lower than those of subsurface layers $(3-5 \mathrm{~cm})$, despite their higher DOC concentrations (Fig. 6), reflecting stronger DOC photobleaching in the surface ice due to the direct exposure to solar irradiation.

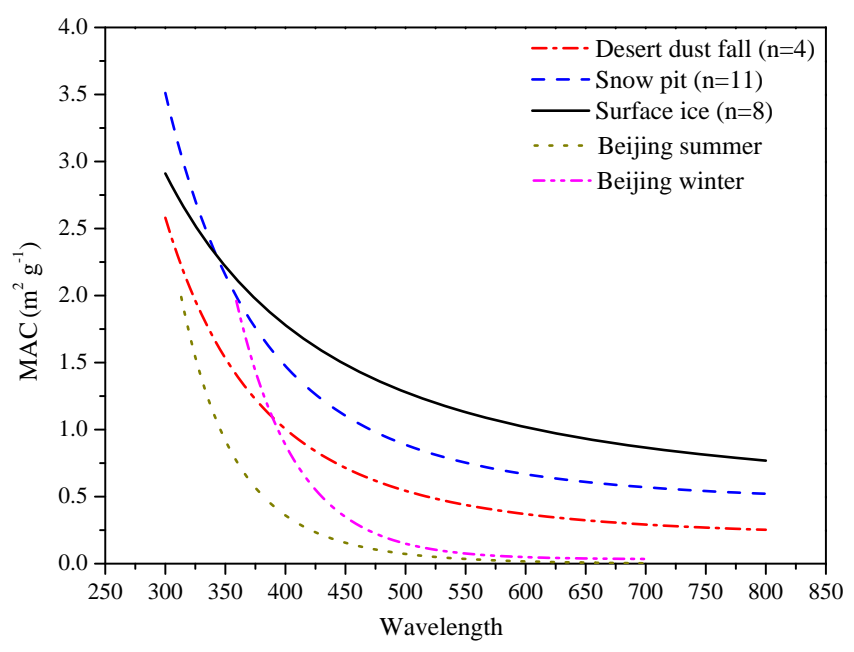

Figure 5. Absorption spectra for DOC in snow and ice of LHG and the dust from surrounding areas.

\subsubsection{Radiative forcing of DOC relative to BC}

Our results showed that the radiative forcing by DOC relative to that of $\mathrm{BC}$ ranged from 2.1 to $30.4 \%(9.5 \pm 8.4 \%)$ for snow pit samples and from 0.01 to $0.5 \%(0.1 \pm 0.1 \%)$ for surface ice samples (Fig. S4 in the Supplement). The high radiative forcing ratio of snow pit samples was caused by its higher DOC/BC $(0.65)$ than that of surface ice $(0.012)$ (Fig. S5 in the Supplement), and the low ratio of DOC/BC in surface ice was caused by enrichment of $\mathrm{BC}$ in surface glacier ice during the intensive ablation period ( $\mathrm{Xu}$ et al., 2009). Snow pit samples can be considered as broadly representative of fresh snow; thus, it is concluded that radiative forcing by DOC is a non-trivial contributor in addition to $\mathrm{BC}$ in reducing the albedo of a glacier when the glacier is covered by fresh snow. The snow pit samples can directly reflect the wet and dry deposition of atmospheric carbonaceous matter in glacierized regions, and the contribution of radiative forcing of snow pit DOC samples is comparable to that 

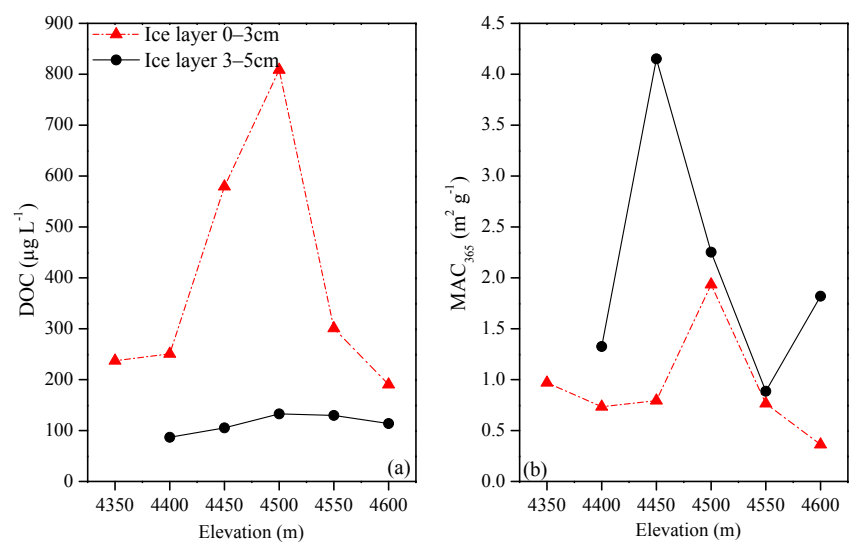

Figure 6. Comparison of DOC concentrations (a) and $\mathrm{MAC}_{365}$ (b) between surface and subsurface ice.

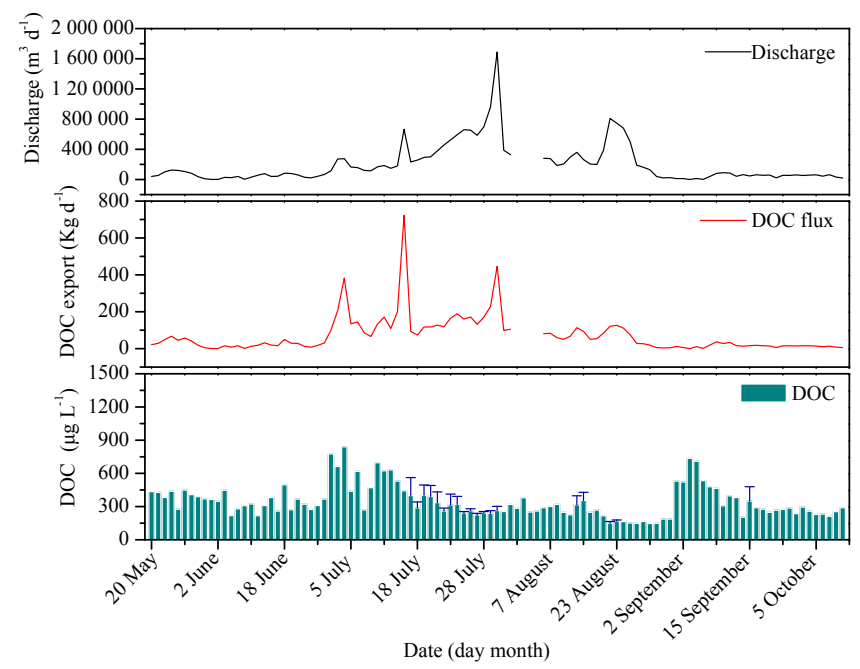

Figure 7. The discharge, DOC concentrations and fluxes exported from LHG in 2015. The concentrations with error bars are used for days with more than one sample.

of water-soluble organic carbon relative to $\mathrm{BC}$ in the atmosphere aerosols to some extent (Kirillova et al., 2014a), but lower than that of aerosols at the top of the atmosphere for the faster decrease of $\mathrm{BC}$ concentrations than brown carbon in the high-altitude atmosphere (Liu et al., 2014).

\subsection{DOC export during the melt season}

The 2-year average discharge-weighted DOC concentration was $238 \pm 96 \mu \mathrm{g} \mathrm{L}^{-1}$ during the melting period. Seasonally, high DOC concentrations appeared during the low discharge periods (May to July and September to October) (Fig. 7), suggesting that DOC concentrations were slightly enriched to some extent. However, there were no clear diurnal variations in DOC concentrations with discharge, suggesting that the discharge from different parts of the glacier was well mixed at the glacier terminus (Fig. S6 in the Supplement).
The seasonal variations in DOC flux were similar to those of the discharge (Fig. 7), indicating that discharge (rather than DOC concentrations) played a dominant role in the DOC mass flux. Hence, the majority of the glacier DOC export occurred during the summer melting season. Over the whole melting season, the annual flux of DOC from LHG was $192 \mathrm{~kg} \mathrm{~km}^{-2} \mathrm{yr}^{-1}$, with peak DOC fluxes occurring from mid-July-late July to late August (70\% of the annual flux). When combined with the value of BDOC determined above, at least $3211 \mathrm{~kg} \mathrm{Cyr}^{-1}$ was ready to be decomposed and returned to the atmosphere as $\mathrm{CO}_{2}$ within 1 month of its release, producing positive feedback in the global warming process.

When considering the entire TP, it is obvious that proglacial stream water DOC concentrations (Table S2 in the Supplement) showed similar spatial variation to those of snow pit DOC (Li et al., 2016), with high and low values being observed on the northern and southern TP, respectively, reflecting strong association between proglacial stream water DOC concentrations and those of snow pit samples. Based on an average proglacial stream water DOC concentration of $193 \mu \mathrm{gL}^{-1}$ (Table S2 in the Supplement) and annual glacial meltwater run-off of $66-68.2 \mathrm{~km}^{3}$ in China (Xie et al., 2006), it was calculated that DOC flux in proglacial stream water of the entire TP glacier was around $12.7-13.2 \mathrm{Gg} \mathrm{C}$ $\left(\mathrm{Gg}=10^{9} \mathrm{~g}\right)$. This estimate is higher than that of DOC deposition $(5.6 \mathrm{Gg} \mathrm{C})$ across the glacierized region of the TP (Li et al., 2016), and agrees well with the negative glaciers' water balance of the TP. Therefore, the TP glaciers can be considered as a carbon source under present environmental conditions.

\section{Conclusions and implications}

The concentrations and light absorption characteristics of DOC on a medium-sized valley glacier on the northern TP were reported in this study. The mean DOC concentrations of snow pit samples, fresh snow, surface ice and proglacial stream water were $332 \pm 132,229 \pm 104,426 \pm 270$ and $238 \pm 96 \mu \mathrm{g} \mathrm{L}^{-1}$, respectively. These values were slightly higher than or comparable with those of other regions (e.g., European Alps and Alaska). DOC in snow pit samples was significantly correlated with $\mathrm{Ca}^{2+}$, a typical cation in mineral dust, indicating that mineral dust transported from adjacent arid regions likely made important contributions to DOC of the studied glacierized regions. In addition, the light absorption profiles of the snow pit DOC were similar to those of dust from potential source deserts. Based on the previously published radiative forcing data for black carbon in snow pits of LHG (Ming et al., 2013), it was estimated that the radiative forcing caused by snow pit DOC was $0.43 \mathrm{~W} \mathrm{~m}^{-2}$, accounting for around $10 \%$ of the radiative forcing caused by BC. Therefore, in addition to BC, DOC is also an important absorber of solar radiation in glacierized regions, especially 
when the glacier is covered by fresh snow. It has also been proven that water-insoluble organic carbon has stronger light absorption ability. Therefore, the total contribution of organic carbon to light absorption in glacierized regions should be higher, which requires further study in the future.

Proglacial stream water represented a well-mixed, integrated contribution from different parts of the glacier, so no clear diurnal variations in DOC concentrations were identified. Combined with discharge and the corresponding DOC concentration, it was calculated that approximately $192.0 \mathrm{~kg} \mathrm{~km}^{-2} \mathrm{yr}^{-1}$ of DOC was released from LHG. It was also estimated that approximate $46.3 \%$ of the DOC could be decomposed within 28 days; thus, $3211 \mathrm{~kg} \mathrm{C} \mathrm{yr}^{-1}$ would return to the atmosphere as $\mathrm{CO}_{2}$, providing the potential for positive feedback in the warming process.

\section{Data availability}

Data on proglacial stream water discharge are available upon request from Professor Xiang Qin. Black carbon data are available upon request from Professor Shichang Kang. Other data are available from Fangping Yan.

\section{The Supplement related to this article is available online at doi:10.5194/tc-10-2611-2016-supplement.}

Acknowledgements. This study was supported by the National Nature Science Foundation of China (41225002, 41271015, 41421061), the State Key Laboratory of Cryospheric Science (SKLCS-ZZ-2015-10 and SKLCS-OP-2014-05), the Chinese Academy of Sciences (KJZD-EW-G03-04) and the Academy of Finland (decision number 268170). The authors gratefully acknowledge the staff of the Qilian Shan Station of Glaciology and Ecological Environment, Chinese Academy of Science, and the anonymous reviewers as well as the editor, Tobias Bolch, for their constructive comments and suggestions.

Edited by: T. Bolch

Reviewed by: two anonymous referees

\section{References}

Andreae, M. O. and Gelencsér, A.: Black carbon or brown carbon? The nature of light-absorbing carbonaceous aerosols, Atmos. Chem. Phys., 6, 3131-3148, doi:10.5194/acp-6-3131-2006, 2006.

Anesio, A. M., Hodson, A. J., Fritz, A., Psenner, R., and Sattler, B.: High microbial activity on glaciers: importance to the global carbon cycle, Global Change Biol., 15, 955-960, 2009.

Anesio, A. M. and Laybourn-Parry, J.: Glaciers and Ice Sheets as a biome, Trends Ecol. Evol., 27, 219-225, 2012.
Antony, R., Mahalinganathan, K., Thamban, M., and Nair, S.: Organic Carbon in Antarctic Snow: Spatial Trends and Possible Sources, Environ. Sci. Technol., 45, 9944-9950, 2011.

Bhatia, M. P., Das, S. B., Longnecker, K., Charette, M. A., and Kujawinski, E. B.: Molecular characterization of dissolved organic matter associated with the Greenland Ice Sheet, Geochim. Cosmochim. Ac., 74, 3768-3784, 2010.

Bolch, T., Kulkarni, A., Kaab, A., Huggel, C., Paul, F., Cogley, J. G., Frey, H., Kargel, J. S., Fujita, K., Scheel, M., Bajracharya, S., and Stoffel, M.: The state and fate of Himalayan glaciers, Science, 336, 310-314, 2012.

Bond, T. C. and Bergstrom, R. W.: Light Absorption by Carbonaceous Particles: An Investigative Review, Aerosol Sci. Technol., 40, 27-67, doi:10.1080/02786820500421521, 2006.

Bosch, C., Andersson, A., Kirillova, E. N., Budhavant, K., Tiwari, S., Praveen, P., Russell, L. M., Beres, N. D., Ramanathan, V., and Gustafsson, Ö.: Source-diagnostic dual-isotope composition and optical properties of water-soluble organic carbon and elemental carbon in the South Asian outflow intercepted over the Indian Ocean, J. Geophys. Res.-Atmos., 119, 11743-11759, 2014.

Chen, Y. and Bond, T. C.: Light absorption by organic carbon from wood combustion, Atmos. Chem. Phys., 10, 1773-1787, doi:10.5194/acp-10-1773-2010, 2010.

Cheng, Y., He, K.-B., Zheng, M., Duan, F.-K., Du, Z.-Y., Ma, Y.L., Tan, J.-H., Yang, F.-M., Liu, J.-M., Zhang, X.-L., Weber, R. J., Bergin, M. H., and Russell, A. G.: Mass absorption efficiency of elemental carbon and water-soluble organic carbon in Beijing, China, Atmos. Chem. Phys., 11, 11497-11510, doi:10.5194/acp11-11497-2011, 2011.

Dong, Z., Qin, D., Chen, J., Qin, X., Ren, J., Cui, X., Du, Z., and Kang, S.: Physicochemical impacts of dust particles on alpine glacier meltwater at the Laohugou Glacier basin in western Qilian Mountains, China, Sci. Total Environ., 493, 930-942, 2014a.

Dong, Z., Qin, D., Kang, S., Ren, J., Chen, J., Cui, X., Du, Z., and Qin, X.: Physicochemical characteristics and sources of atmospheric dust deposition in snow packs on the glaciers of western Qilian Mountains, China, Tellus B, 66, 20956, doi:10.3402/tellusb.v66.20956, 2014b.

Du, W., Qin, X., Liu, Y. S., and Wang, X. F.: Variation of Laohugou Glacier No. 12 in Qilian Mountains, J. Glaciol. Geocryol., 30, 373-379, 2008.

Hagler, G. S. W., Bergin, M. H., Smith, E. A., Dibb, J. E., Anderson, C., and Steig, E. J.: Particulate and water-soluble carbon measured in recent snow at Summit, Greenland, Geophys. Res. Lett., 34, L16505, doi:10.1029/2007GL030110, 2007.

Hattori, Y., Suzuki, K., Honda, M., and Shimizu, H.: Re-Os isotope systematics of the Taklimakan Desert sands, moraines and river sediments around the Taklimakan Desert, and of Tibetan soils, Geochim. Cosmochim. Ac., 67, 1203-1213, 2003.

Hecobian, A., Zhang, X., Zheng, M., Frank, N., Edgerton, E. S., and Weber, R. J.: Water-Soluble Organic Aerosol material and the light-absorption characteristics of aqueous extracts measured over the Southeastern United States, Atmos. Chem. Phys., 10, 5965-5977, doi:10.5194/acp-10-5965-2010, 2010.

Hood, E. and Scott, D.: Riverine organic matter and nutrients in southeast Alaska affected by glacial coverage, Nat. Geosci., 1, 583-587, 2008.

Hood, E., Fellman, J., Spencer, R. G., Hernes, P. J., Edwards, R., D'Amore, D., and Scott, D.: Glaciers as a source of ancient and 
labile organic matter to the marine environment, Nature, 462 , 1044-1047, 2009.

Hood, E., Battin, T. J., Fellman, J., O’Neel, S., and Spencer, R. G. M.: Storage and release of organic carbon from glaciers and ice sheets, Nat. Geosci., 8, 91-96, 2015.

Huang, J., Kang, S., Guo, J., Sillanpää, M., Zhang, Q., Qin, X., Du, W., and Tripathee, L.: Mercury distribution and variation on a high-elevation mountain glacier on the northern boundary of the Tibetan Plateau, Atmos. Environ., 96, 27-36, 2014.

Jacob, T., Wahr, J., Pfeffer, W. T., and Swenson, S.: Recent contributions of glaciers and ice caps to sea level rise, Nature, 482, 514-518, 2012.

Kang, S., Mayewski, P. A., Qin, D., Yan, Y., Hou, S., Zhang, D., Ren, J., and Kruetz, K.: Glaciochemical records from a Mt. Everest ice core: relationship to atmospheric circulation over Asia, Atmos. Environ., 36, 3351-3361, 2002.

Kang, S., Huang, J., and Xu, Y.: Changes in ionic concentrations and $\delta^{18} \mathrm{O}$ in the snowpack of Zhadang glacier, Nyainqentanglha mountain, southern Tibetan Plateau, Ann. Glaciol., 49, 127-134, 2008.

Kang, S., Wang, F., Morgenstern, U., Zhang, Y., Grigholm, B., Kaspari, S., Schwikowski, M., Ren, J., Yao, T., Qin, D., and Mayewski, P. A.: Dramatic loss of glacier accumulation area on the Tibetan Plateau revealed by ice core tritium and mercury records, The Cryosphere, 9, 1213-1222, doi:10.5194/tc-9-12132015, 2015.

Kaspari, S., Painter, T. H., Gysel, M., Skiles, S. M., and Schwikowski, M.: Seasonal and elevational variations of black carbon and dust in snow and ice in the Solu-Khumbu, Nepal and estimated radiative forcings, Atmos. Chem. Phys., 14, 80898103, doi:10.5194/acp-14-8089-2014, 2014.

Kehrwald, N. M., Thompson, L. G., Tandong, Y., MosleyThompson, E., Schotterer, U., Alfimov, V., Beer, J., Eikenberg, J., and Davis, M. E.: Mass loss on Himalayan glacier endangers water resources, Geophys. Res. Lett., 35, L22503, doi:10.1029/2008GL035556, 2008.

Kirchstetter, T. W.: Evidence that the spectral dependence of light absorption by aerosols is affected by organic carbon, J. Geophys. Res., 109, D21208, doi:10.1029/2004JD004999, 2004.

Kirillova, E. N., Andersson, A., Han, J., Lee, M., and Gustafsson, Ö.: Sources and light absorption of water-soluble organic carbon aerosols in the outflow from northern China, Atmos. Chem. Phys., 14, 1413-1422, doi:10.5194/acp-14-1413-2014, 2014a.

Kirillova, E. N., Andersson, A., Tiwari, S., Srivastava, A. K., Bisht, D. S., and Gustafsson, Ö.: Water-soluble organic carbon aerosols during a full New Delhi winter: Isotope-based source apportionment and optical properties, J. Geophys. Res.-Atmos., 119, 3476-3485, 2014b

Lambe, A. T., Cappa, C. D., Massoli, P., Onasch, T. B., Forestieri, S. D., Martin, A. T., Cummings, M. J., Croasdale, D. R., Brune, W. H., and Worsnop, D. R.: Relationship between oxidation level and optical properties of secondary organic aerosol, Environ. Sci. Technol., 47, 6349-6357, 2013.

Lau, W. K. M., Kim, M.-K., Kim, K.-M., and Lee, W.-S.: Enhanced surface warming and accelerated snow melt in the Himalayas and Tibetan Plateau induced by absorbing aerosols, Environ. Res. Lett., 5, 025204, doi:10.1088/1748-9326/5/2/025204, 2010.

Lawson, E. C., Wadham, J. L., Tranter, M., Stibal, M., Lis, G. P., Butler, C. E. H., Laybourn-Parry, J., Nienow, P., Chandler, D., and Dewsbury, P.: Greenland Ice Sheet exports labile organic carbon to the Arctic oceans, Biogeosciences, 11, 4015-4028, doi:10.5194/bg-11-4015-2014, 2014.

Legrand, M., Preunkert, S., Jourdain, B., Guilhermet, J., Faïn, X., Alekhina, I., and Petit, J. R.: Water-soluble organic carbon in snow and ice deposited at Alpine, Greenland, and Antarctic sites: a critical review of available data and their atmospheric relevance, Clim. Past, 9, 2195-2211, doi:10.5194/cp-9-2195-2013, 2013.

Levinson, R., Akbari, H., and Berdahl, P.: Measuring solar reflectance - Part I: Defining a metric that accurately predicts solar heat gain, Sol. Energy, 84, 1717-1744, 2010.

Li, C., Kang, S., Zhang, Q., and Kaspari, S.: Major ionic composition of precipitation in the Nam Co region, Central Tibetan Plateau, Atmos. Res., 85, 351-360, 2007.

Li, C., Chen, P., Kang, S., Yan, F., Li, X., Qu, B., and Sillanpää, M.: Carbonaceous matter deposition in the high glacial regions of the Tibetan Plateau, Atmos. Environ., 141, 203-208, 2016.

Li, J., Qin, X., Sun, W., Zhang, M., and Yang, J.: Analysis on Micrometerological Characteristic in the Surface Layer of Laohugou Glacier No.12 Qilian Mountains, Plateau Meteorol., 31, 370-379, 2012.

Li, Z., Li, H., Dong, Z., and Zhang, M.: Chemical characteristics and environmental significance of fresh snow deposition on Urumqi Glacier No. 1 of Tianshan Mountains, China, Chin. Geogr. Sci., 20, 389-397, 2010.

Liu, J., Scheuer, E., Dibb, J., Ziemba, L. D., Thornhill, K., Anderson, B. E., Wisthaler, A., Mikoviny, T., Devi, J. J., and Bergin, M.: Brown carbon in the continental troposphere, Geophys. Res. Lett., 41, 2191-2195, 2014.

May, B., Wagenbach, D., Hoffmann, H., Legrand, M., Preunkert, S., and Steier, P.: Constraints on the major sources of dissolved organic carbon in Alpine ice cores from radiocarbon analysis over the bomb-peak period, J. Geophys. Res.-Atmos., 118, 33193327, 2013.

Ming, J., Xiao, C., Du, Z., and Yang, X.: An overview of black carbon deposition in High Asia glaciers and its impacts on radiation balance, Adv. Water Resour., 55, 80-87, 2013.

Nair, V. S., Babu, S. S., Moorthy, K. K., Sharma, A. K., Marinoni, A., and Ajai: Black carbon aerosols over the Himalayas: direct and surface albedo forcing, Tellus B, 65, 19738, doi:10.3402/tellusb.v65i0.19738, 2013.

Neckel, N., Kropáček, J., Bolch, T., and Hochschild, V.: Glacier mass changes on the Tibetan Plateau 2003-2009 derived from ICESat laser altimetry measurements, Environ. Res. Lett., 9, 014009, doi:10.1088/1748-9326/9/1/014009, 2014.

Qu, B., Ming, J., Kang, S.-C., Zhang, G.-S., Li, Y.-W., Li, C.-D., Zhao, S.-Y., Ji, Z.-M., and Cao, J.-J.: The decreasing albedo of the Zhadang glacier on western Nyainqentanglha and the role of light-absorbing impurities, Atmos. Chem. Phys., 14, 11117 11128, doi:10.5194/acp-14-11117-2014, 2014.

Singer, G. A., Fasching, C., Wilhelm, L., Niggemann, J., Steier, P., Dittmar, T., and Battin, T. J.: Biogeochemically diverse organic matter in Alpine glaciers and its downstream fate, Nat. Geosci., 5, 710-714, 2012.

Spencer, R. G. M., Stubbins, A., Hernes, P. J., Baker, A., Mopper, K., Aufdenkampe, A. K., Dyda, R. Y., Mwamba, V. L., Mangangu, A. M., and Wabakanghanzi, J. N.: Photochemical degradation of dissolved organic matter and dissolved lignin phenols 
from the Congo River, J. Geophys. Res.-Biogeosciences, 114, G03010, doi:10.1029/2009JG000968, 2009.

Spencer, R. G. M., Guo, W., Raymond, P. A., Dittmar, T., Hood, E., Fellman, J., and Stubbins, A.: Source and biolability of ancient dissolved organic matter in glacier and lake ecosystems on the Tibetan Plateau, Geochim. Cosmochim. Ac., 142, 64-74, 2014.

Stubbins, A., Hood, E., Raymond, P. A., Aiken, G. R., Sleighter, R. L., Hernes, P. J., Butman, D., Hatcher, P. G., Striegl, R. G., Schuster, P., Abdulla, H. A. N., Vermilyea, A. W., Scott, D. T., and Spencer, R. G. M.: Anthropogenic aerosols as a source of ancient dissolved organic matter in glaciers, Nat. Geosci., 5, 198201, 2012.

Voisin, D., Jaffrezo, J. L., Houdier, S., Barret, M., Cozic, J., King, M. D., France, J. L., Reay, H. J., Grannas, A., and Kos, G.: Carbonaceous species and humic like substances (HULIS) in Arctic snowpack during OASIS field campaign in Barrow, J. Geophys. Res., 117, D00R19, doi:10.1029/2011JD016612, 2012

Wu, X., LI, Q., Wang, L., Pu, J., He, J., and Zhang, C.: Regional characteristics of ion concentration in glacial snowpits over the Tibetan Plateau and source analysis, Environ. Sci., 32, 971-975, 2011.

Xie, Z., Wang, X., Kang, E., Feng, Q., Li, Q., and Cheng, L.: Glacial runoff in China: an evaluation and prediction for the future 50 years, J. Glaciol. Geocryol., 28, 457-466, 2006.

Xu, B., Cao, J., Hansen, J., Yao, T., Joswia, D. R., Wang, N., Wu, G., Wang, M., Zhao, H., and Yang, W.: Black soot and the survival of Tibetan glaciers, P. Natl. Acad. Sci., 106, 22114-22118, 2009.
Xu, J., Zhang, Q., Li, X., Ge, X., Xiao, C., Ren, J., and Qin, D.: Dissolved organic matter and inorganic ions in a central Himalayan glacier - insights into chemical composition and atmospheric sources, Environ. Sci. Technol., 47, 6181-6188, 2013.

Yan, F., Kang, S., Chen, P., Li, Y., Hu, Z., and Li, C.: Concentration and source of dissolved organic carbon in snowpits of the Tibetan Plateau, Environ. Sci., 8, 2827-2832, 2015.

Yao, T.: Relationship between calcium and atmospheric dust recorded in Guliya ice core, Chin. Sci. Bull., 49, 706-710, 2004.

Yao, T., Thompson, L., Yang, W., Yu, W., Gao, Y., Guo, X., Yang, X., Duan, K., Zhao, H., Xu, B., Pu, J., Lu, A., Xiang, Y., Kattel, D. B., and Joswiak, D.: Different glacier status with atmospheric circulations in Tibetan Plateau and surroundings, Nat. Clim. Change, 2, 663-667, doi:10.1038/nclimate1580, 2012.

Zhang, Q., Huang, J., Wang, F., Mark, L., Xu, J., Armstrong, D., Li, C., Zhang, Y., and Kang, S.: Mercury distribution and deposition in glacier snow over western China, Environ. Sci. Technol., 46, 5404-5413, 2012a.

Zhang, Y., Liu, S., Shangguan, D., Li, J., and Zhao, J.: Thinning and shrinkage of Laohugou No. 12 glacier in the Western Qilian Mountains, China, from 1957 to 2007, J. Mount. Sci., 9, 343350, 2012b.

Zhao, R., Lee, A. K. Y., Huang, L., Li, X., Yang, F., and Abbatt, J. P. D.: Photochemical processing of aqueous atmospheric brown carbon, Atmos. Chem. Phys., 15, 6087-6100, doi:10.5194/acp15-6087-2015, 2015. 